\title{
Mapping of Agricultural Area Using Multitemporal Remote Sensing Images
}

\author{
多時期リモートセンシング画像による農地のマッピング
}

\author{
Lin ZHU and Ryutaro TATEISHI \\ 朱＼cjkstart林・建石隆太郎
}

\begin{abstract}
A new method is proposed for agricultural area mapping using multitemporal satellite Landsat TM images. This statistical method is designed for the discrimination of agricultural area and non-agricultural area and crop identification, based on the fusion of multitemporal multispectral data. In the proposed algorithm, an important role is played by the transition probabilities, which take into account the temporal dependence of images. The transition probabilities are estimated directly from the pattern of Landsat TM NDVI. The feasibility of the new method is verified by experimental results.
\end{abstract}

和文概要：多時期ランドサット TM 画像を用いた農 業地域のマッピングにおいて, 新しい方法を提案した。 多時期マルチスペクトルデータのフュージョンに基づ いた統計的手法を用いることにより農地，非農地の区 別や農作物の判別を行う方法である。本研究のアルゴ リズムにおいて，デー夕の時間的依存性を考慮に入れ た推移確率が重要な役割を果たしている。推移確率は, ランドサットTM データにおけるNDVIの変化パ ターンから求められる。本研究における手法は, 実験 的にその有効性が実証された。

\section{INTRODUCTION}

In many countries, agriculture forms the basis of economy and provides the stable food of the people. It is essential to make fully and reasonably use of the land resources and environmental capacity. The effective management decisions may be correctly made only on real-time information about land resources status and its development. Ability to provide up-to-date agricultural information shows

Center for Environment Remote Sensing (CEReS), Chiba University, 1-33, Yayoi-cho, Inage-ku, Chiba, 263-8522 Japan

「写真測量とリモートセンシング」VOL. 39, NO. 1， 2000 increasing importance and urgency. Thus, for socio -economic and global environmental aspects, an effective agricultural area mapping and monitoring program are necessary at local, national and international scale. Accurate crop maps are also required for a variety of applications ranging from general inventory requirements to ecological studies.

Remote sensing has shown great potential in agricultural mapping due to its advantages over traditional procedures in terms of cost effectiveness and timeliness in the availability of information over larger areas. The most commonly used image data have been Landsat Thematic Mapper (TM) digital data, which, due to their spectral and spatial characteristics, allow the characteristics of the territory to be analyzed with enough accuracy and may be used for effective management of natural resources ${ }^{1)}$. The single date image may not provide enough information for reliable classification, usually temporal variations of spectrum in the images that caused by the changes of vegetation cover and soil moisture are used to enhance the separability of terrain categories and provide increased interpretation capabilities. Thus multitemporal images have 
been used to satisfy the purpose of developing an accurate agricultural mapping.

Because of the spectrum similarity of agricultural crops, it is still difficult to achieve reliable interpretation result using conventional classification methods, which usually ignore the time interval between the acquisition of images. This problem may be overcome by using crop seasonal differences. The combination of temporal sequences of images with ancillary knowledge on phenology can be effective method for agricultural mapping.

A few studies have been concerned in incorporating temporal dependence of images acquired at different time ${ }^{2334)}$, but the unavoidable problem is that how to decide the transition probability, which represents the degree of consistence between images. Usually the transition probabilities have been roughly estimated by experience, i. e. from historical observations, from ground sampling, from observation of areas having similar ground cover and utilization. There should be theoretical and reasonable basis on transition probabilities estimation.

It is well known that vegetation index has a special characteristic due to its distinct annual and seasonal changes, it is also a sensitive indicator on the study of global and regional environment change caused by climate or human activities ${ }^{5 / 6) 77}$. Normalized difference vegetation index (NDVI) is nodoubtedly the most widely used vegetation index for global and regional land cover change study, thus it is reasonable to use NDVI for the detection and quantitative assessment of land cover/land use change. Transition probabilities represent the change relationship of land cover between images in a time-varying environment. Thus, we can suppose that there should be some relations between the change pattern of NDVI and the transition probabilities, we try to establish the relationship theoretically between the change pattern of NDVI and the transition probabilities, and consequently achieve an accurate agricultural mapping.

Many studies have been concentrated in agricul- tural area mapping using multitemporal data, but how to use temporal dependence of images is still a new challenge, here we included the concepts of time and phenology changes based on temporal data fusion model to develop a new method of agricultural mapping using multitemporal Landsat TM images.

\section{METHOD}

\subsection{Temporal data fusion on a Bayesian formula- tion}

In this section, we will discuss the problem based on a Bayesian formulation. When multitemporal data are used to the classification, the time interval between the acquisition of the data from different sensors has normally been ignored in the sense that it is usually assumed that the images are acquired at almost the same time, or that no changes with respect to the pattern classes have occurred between the acquisition dates. The change of classes and temporal dependence should not be ignored. Let us consider that two multispectral remote sensing images acquired at times $t_{1}$ and $t_{2}$ on the same area are examined. Let us think that a pixel of the multispectral image acquired at time $t_{1}$ and a spatially corresponding pixel of multispectral image acquired at time $t_{2}$. These pixels are characterized by the m-variate observation feature vectors $X_{1}$ and $X_{2}$, respectively. Let $\omega_{i}(i=1,2, \cdots, n)$ and $\nu_{k}(k=1,2$, $\cdots, n)$ be the set of possible land cover classes at time $t_{1}$ and $t_{2}$ respectively, here we assume that no other classes occur between the period of time $t_{1}$ and $t_{2}$. An appropriate set of discrimination functions for a Bayes optimal classification strategy, i. e., the set of a posteriori probabilities can be used to decide whether the two classes $\omega_{i}$ and $\nu_{k}$, to which the considered couple of pixels are assigned, are different or not.

Here we only consider pixel-based fusion, contextual information will be disregarded in the spatial domain, i. e., if we classify each couple of pixels independently of any other on the basis only of its 
feature vectors $X_{1}$ and $X_{2}$, based on the Bayes rule, it requires that the couple of classes $\left(\omega_{i}, \nu_{k}\right)$ be selected that provides the maximum likelihood $\zeta\left(\omega_{i}, \nu_{k}\right)$, given the observed feature vectors $X_{1}$ and $X_{2}$,

$\max \zeta\left(\omega_{i}, \nu_{k}\right)=\max \left\{P\left(\omega_{i}, \nu_{k} \mid X_{1}, X_{2}\right)\right\}$

The a posteriori probability in ( 1 ) can be represented as the following formula:

$P\left(\omega_{i}, \nu_{k} \mid X_{1}, X_{2}\right)=$

$\frac{P\left(X_{1}, X_{2} \mid \omega_{i}, \nu_{k}\right) P\left(\nu_{k} \mid \omega_{i}\right) P\left(\omega_{i}\right)}{P\left(X_{1}, X_{2}\right)}$

$$
P\left(X_{1}, X_{2}\right)
$$

where the term $P\left(X_{1}, X_{2}\right)$ can be neglected, as it is independent of $\omega_{i}$ and $\nu_{k}$.

It is difficult to calculate (2), fortunately we can introduce the following hypothesis to simplify the estimation of such functions ${ }^{388}$.

Let us consider the feature vector $X_{i}(i=1,2)$ related to time $t_{i}$, be composed of a signal component $S_{i}$ and of a noise component $N_{i}$, moreover, the signal $S_{i}$ depends only on the land cover class at time $t_{i}$, and the noise $N_{i}$ also depends only on the land cover class at time $t_{i}$ and possibly on $S_{i}$. Under this hypothesis, the probabilistic dependence between the images at the two times derives only from the dependence of the classes at the two times, that means the feature vector $X_{1}$ and $X_{2}$ are independent, and can be written as :

$P\left(X_{1}, X_{2} \mid \omega_{i}, \nu_{k}\right)=P\left(X_{1} \mid \omega_{i}\right) P\left(X_{2} \mid \nu_{k}\right)$

By substituting ( 3 ) into (2) and by applying some transformations, the likelihood function that will be used in the decision rule now takes the following form :

$\zeta\left(\omega_{i}, \nu_{k}\right)=P\left(\omega_{i} \mid X_{1}\right) P\left(\nu_{k} \mid X_{2}\right) \frac{P\left(\nu_{k} \mid \omega_{i}\right)}{P\left(\nu_{k}\right)}$

According to formula (4), to perform the classification of two multitemporal remote sensing images, we need to estimate the a priori probabilities $P\left(\nu_{k}\right)$ of the classes at time $t_{2}$, the single date, multivariate conditional probabilities $P\left(\omega_{i} \mid X_{1}\right)$ and $P\left(\nu_{k} \mid X_{2}\right)$ at the two times, and the transition probabilities $P\left(\nu_{k} \mid \omega_{i}\right)$, which represent the probabilities of the change of classes from time $t_{1}$ to time $t_{2}$. Now the problem is how to decide the transition probabil- ities.

\subsection{Determination of transition probabilities}

Formerly, the transition probabilities were decided empirically ${ }^{3 / 4}$, but these were neither accurate nor reasonable. Also, it is difficult to detect land cover changes. It should be more reasonable to decide transition probability using the change pattern of NDVI.

We can use the change of NDVI to represent the seasonal change of vegetation and the change of classes. Let us name the change pattern of NDVI, which are calculated from the training data set and decided by the predetermined thresholds, based on the analysis of the change of NDVI, as the estimated change pattern (ECP). The estimated change pattern (ECP) of Landsat TM NDVI are defined as: If $\xi_{2} \leq \Delta N D V I \leq \xi_{1}$, then $\mathrm{ECP}=0$

If $\triangle N D V I>\xi_{1}$, then $\mathrm{ECP}=1$

If $\triangle N D V I<\xi_{2}$, then $\mathrm{ECP}=-1$

$\triangle N D V I$ is the difference of the NDVI value between time $t_{1}$ to time $t_{2} . \xi_{1}$ and $\xi_{2}$ are the thresholds to decide the estimated change pattern (ECP) of NDVI from time $t_{1}$ to time $t_{2}$.

The change pattern of NDVI, which are calculated directly from the classification processing of images and derived as the same as formulation ( 5 ), are named as the actual change pattern (ACP). By comparing NDVI estimated change pattern (ECP) to NDVI actual change pattern (ACP) calculated from images, the transition probabilities $P\left(\nu_{k} \mid \omega_{i}\right)$ are defined as follows:

If $\omega_{i}=\nu_{k}$ and ACPECP, then the transition probabilities $P\left(\nu_{k} \mid \omega_{i}\right)=1$;

If $\omega_{i}=\nu_{k}$ but $\mathrm{ACP} \neq \mathrm{ECP}$, then

$P\left(\nu_{k} \mid \omega_{i}\right)=\alpha \frac{P\left(\omega_{i} \mid X_{1}\right)}{P_{1}(\max )} \frac{P\left(\nu_{k} \mid X_{2}\right)}{P_{2}(\max )}$

If $\omega_{i} \neq \nu_{k}$ and $\mathrm{ACP} \neq \mathrm{ECP}$, then $P\left(\nu_{k} \mid \omega_{i}\right)=0$

If $\omega_{i} \neq \nu_{k}$ but $\mathrm{ACP}=\mathrm{ECP}$, then

$P\left(\nu_{k} \mid \omega_{i}\right)=\beta \frac{P\left(\omega_{i} \mid X_{1}\right)}{P_{1}(\max )} \frac{P\left(\nu_{k} \mid X_{2}\right)}{P_{2}(\max )}$

where $P_{1}(\max )$ and $P_{2}(\max )$ are the maximum $a$ posteriori probability among the different classes at 
time $t_{1}$ and $t_{2}$, respectively. $\alpha$ and $\beta$ are user-specified constants which control the degree of consistency between the temporal data.

For multitemporal data fusion more than two images, let us consider the $\mathrm{m}$-variate observation feature vectors $X^{t}$ and the set of possible land cover classes $C_{i}^{t}(i=1,2, \cdots, n)$ related to time $t(t=1,2, \cdots$, $p)$, based on Bayesian formulation and Markov property, the a posteriori probability can be easily obtained as follows :

$$
\begin{aligned}
& P\left(C^{1}, C^{2}, \cdots, C^{p} \mid X^{1}, X^{2}, \cdots, X^{p}\right)= \\
& \frac{P\left(C^{1} \mid X^{1}\right) \cdots P\left(C^{p} \mid X^{p}\right) P\left(C^{2} \mid C^{1}\right) \cdots P\left(C^{p} \mid C^{p-1}\right)}{P\left(C^{2}\right) P\left(C^{3}\right) \cdots P\left(C^{p}\right)}
\end{aligned}
$$

we can calculate the transition probabilities $P\left(C^{p} \mid C^{p-1}\right)$ respectively, then obtain the maximum of $(7)$.

\section{EXPERIMENT}

\subsection{Study area}

The study area is located in the region of Zhangwu county, a typical agricultural area of Liaoning province in the north-east part of China. The image size is $1024 \times 1024$ pixels, corresponding to $25.6 \times$ $25.6 \mathrm{~km}^{2}$, with geographical coordinates from $42^{\circ} 22$ $6^{\prime \prime} \mathrm{N}$ to $42^{\circ} 35^{\prime} 50^{\prime \prime} \mathrm{N}$ in latitude and from $122^{\circ} 12^{\prime} 56^{\prime \prime} \mathrm{E}$ to $122^{\circ} 31^{\prime} 50^{\prime \prime} \mathrm{E}$ in longitude.

Zhangwu's economy is oriented toward agriculture, producing mainly crops such as corn and grain, as well as soybean, wheat, pachyrhizus, peanut, and tobacco. The main crop season in this area is from April to October, including the driest month July.

The ground survey trip was carried out in July 1999, cooperated with the agricultural extension office of Zhangwu county and assisted by Institute of Remote Sensing Application of Chinese Academy of Sciences. The ground truth data of the study area were collected for all land cover types and the site locations were accurately fixed using the ERSDAC Navigator GPS system developed by DOWA ENGINEERING CO., LTD of Japan. As there is an time interval between the ground survey and the acquisition of satellite data, the previous records provided by the local agricultural technology stations were investigated, also the field check was carried out with consultation with agricultural advisers accompanied and farmers, only the confirmed sites that no land cover change occurred were selected as ground truth data. The classification of the following land cover classes is considered: corn, paddy, soybean, wheat, meadow, poplar, pine, bare land, urban, water, dried area and deforest area. The collected ground truth data were used for training samples of supervised classification and accuracy assessment.

\subsection{Data acquisition and preprocessing}

The multitemporal Landsat TM images (Path 120, Row 30) collected on 19 May, 1994 and 23 August, 1994 were selected for this study, mainly because these are the best available cloud-free scenes in the crop season. In temporal study, it is important to compensate for the difference in sun elevation angle throughout one year and the influence of changes in atmospheric conditions in order to extract only the spectral change of the land object. Relative radiometric correction was performed on multitemporal images ${ }^{10)}$ : several ground objects were selected as the reference points, these reference points have either high spectral reflectivity or low reflectivity, the reflectance characteristics of these points was believed that would not change temporally. The image of May was selected as the reference image. The digital number values of 12 reference points were used in a regression analysis to calculate the coefficients for transformation, so that both the influences of atmospheric conditions and sun elevation angle were removed. Multitemporal TM data were co-registered and resampled to $25 \mathrm{~m}$ pixel size, then geometrically corrected in UTM projection using the nearest neighbor method. The RMS error less than 1 pixel was yielded. Six channels of TM data were used except the thermal channel 6 . Figure 1 shows the false color composite images of the test site.

For the study of temporal data fusion, the normal- 


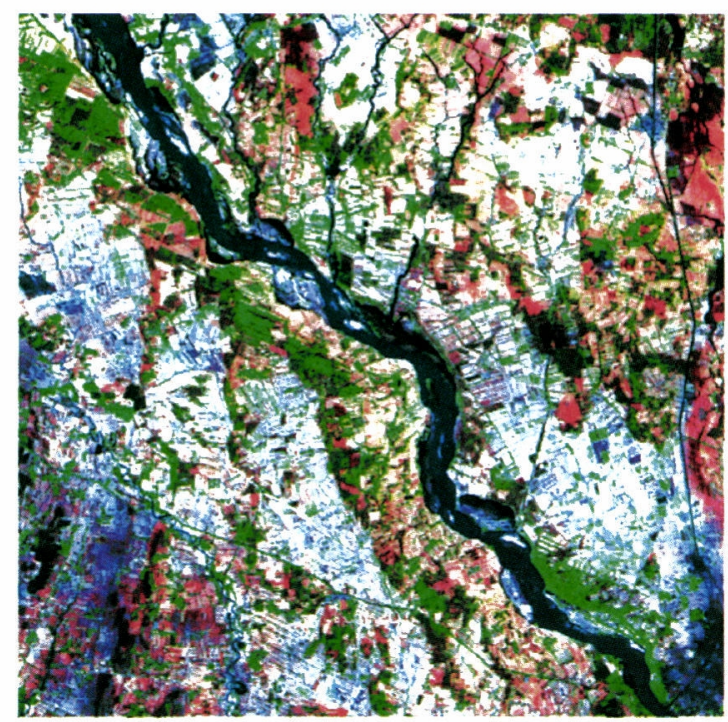

(a)

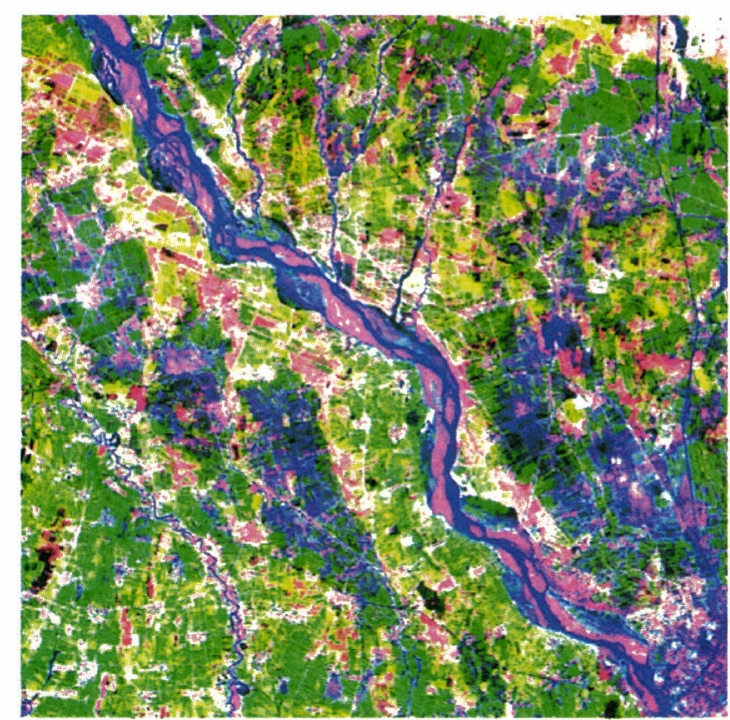

0

$10 \mathrm{~km}$

(b)

Figure 1 Data utilized for experiments: the false color composite images (channel 5, 4, 3 for red, green and blue) of Landsat TM data acquired ( a ) in May 1994 and (b) in August 1994.

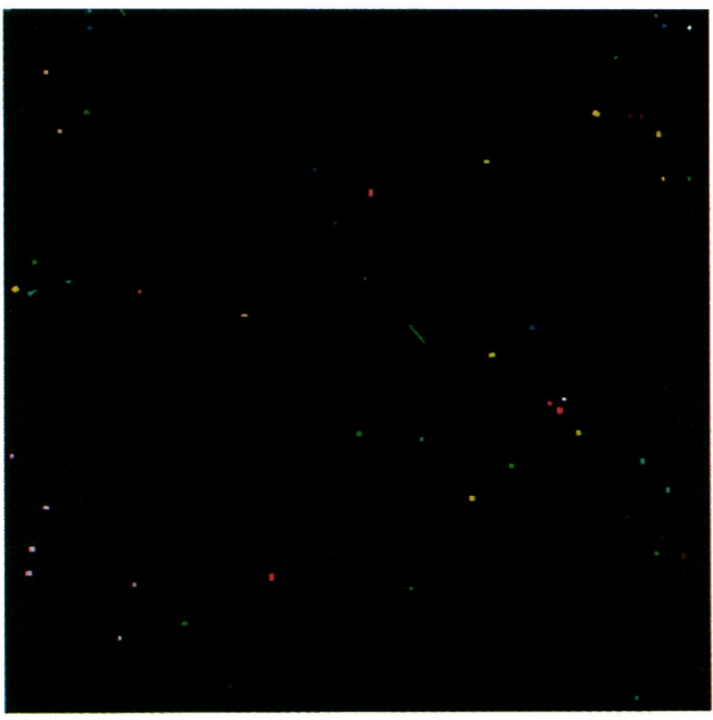

(a)

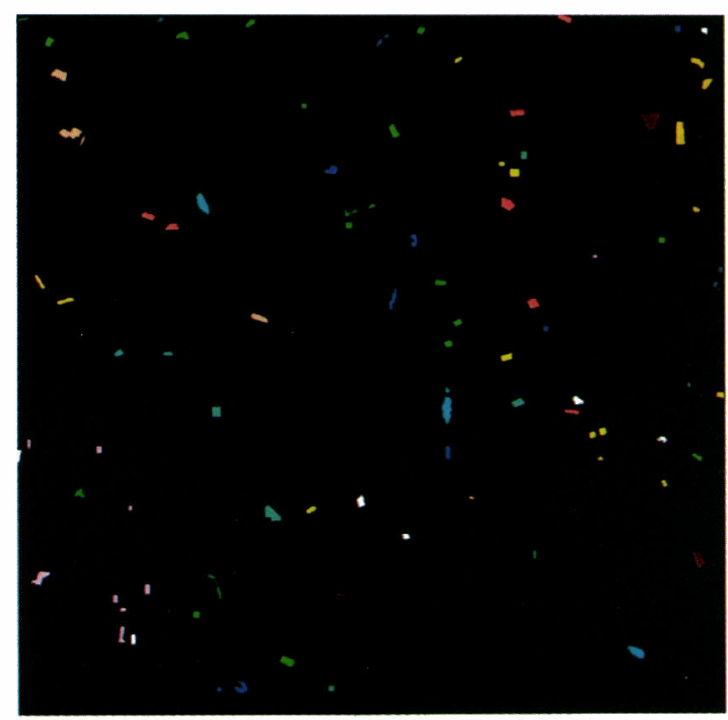

( b )

Figure 3 Training data set ( $a$ ) and testing data set ( $b$ ) used for supervised classification and accuracy assessment.

ized difference vegetation index (NDVI) defined by the equation ( 8 ) was used.

$\mathrm{NDVI}=(\mathrm{TM} 4-\mathrm{TM} 3) /(\mathrm{TM} 4+\mathrm{TM} 3)$

TM3 and TM4 are Landsat TM channel 3 and channel 4, respectively. The NDVI equation produces values in the range of -1.0 to 1.0 , where increasing positive values indicate increasing green vegetation and negative values indicate non 


\section{NDVI CHANGE PATTERN}

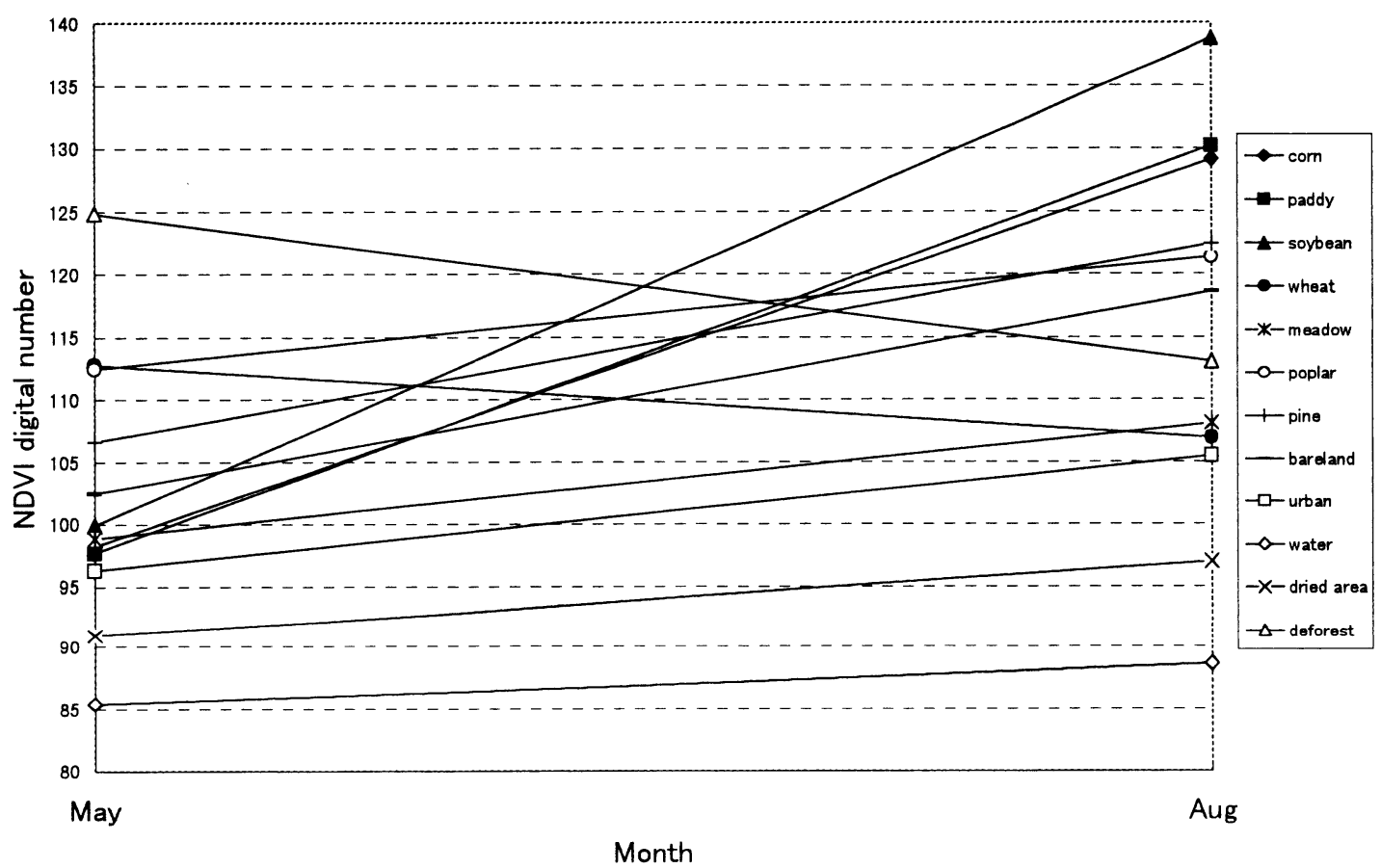

Figure 2 Landsat TM NDVI change pattern profile

-vegetated surface features such as water, barren, ice, and snow or clouds. The NDVI data were scaled to integer value from 0 to 200 , in which the least significant digit represents 1.0 percent of the total possible. Figure 2 shows the multi-temporal NDVI profile.

\subsection{Selection of training and testing data set}

How to choose a suitable training and testing data set is one of the most important problems. The characteristics of the training data for supervised classification have a considerable influence on the quality of the classification result. However, there is no exact standard for choosing the correct training and testing data. It is essential that the training data provide a representative description of each class. Investigations of the effect of training data set characteristics on the performance of classifications have revealed that factors such as training data set size and composition have a major effect on classification accuracy. For conventional statistical clas- sifiers, it is important that the size of the training data set for each class be at least 10-30 times the number of discriminating wavebands ${ }^{9}$. Considering about the effect of other variables, the training data set size for each class was selected all about 100-300 pixels. Figure 3 (a) shows the selected training data set.

Classification accuracy is the important quantitative index that expresses the quality of a supervised image classification. Typically, classification accuracy is assessed by comparing the predicted class of membership derived from the classification with the actual class of membership on the ground. The nature of the testing data set should have a significant effect on the resulting accuracy statement. It is essential that the testing data set must also be representative of the classes. Therefore the testing data set should be strictly picked up from across the whole site and the sample large enough.

The way in which the classification accuracy be assessed is that similar two data sets were selected 
independently from ground truth before classification, then one was selected randomly as the training data set, and the other one used as the testing data set for evaluating of classification accuracy. Here, in order to evaluate the classification accuracy more precisely, the testing data set was selected more than almost three times of the training data set. Figure 3(b) shows the selected testing data set.

\subsection{Parameter selection}

The transition probabilities represent the degree of consistence between images acquired at different time and have the great influence on classification accuracy. In our temporal fusion model, transition probabilities are estimated directly from the change pattern of NDVI, thus how to decide the thresholds $\xi_{1}$ and $\xi_{2}$ is very important. It is essential that the specification of $\xi_{1}$ and $\xi_{2}$ should make the classes to be more easily separated. As shown in the multitemporal NDVI change profile, the NDVI change directions and magnitudes of classes are different. We firstly derived the NDVI values of different classes from the training data set of May and August, respectively, then we calculated the change values $\triangle N D V I$ between all the same classes and different classes from May to August, finally, we deliberated the results and selected the most appropriate thresholds. For the detailed procedure, we tried to separate all $\triangle N D V I$ values into three groups evenly : increasing, decreasing and constant. The $\triangle N D V I$ values between the same classes were examined, as shown in Table 1, except the value -5.83 of wheat, all values of other 11 classes are above 0 , moreover, in this study, actually no class has the value of 0 which means no NDVI change occurred. Thus, the 11 classes which have the value above 0 should be divided into two groups according to the magnitude of the change of NDVI, one for

Table 1 The change values of NDVI of all classes between May 1994 and August 1994.

\begin{tabular}{|c|c|c|c|c|c|c|c|c|c|c|c|c|}
\hline May & Corn & Paddy & Bean & Wheat & Meadow & Poplar & Pine & $\begin{array}{l}\text { Bare } \\
\text { land }\end{array}$ & Urban & Water & $\begin{array}{l}\text { Dried } \\
\text { area }\end{array}$ & $\begin{array}{l}\text { Deforest } \\
\text { area }\end{array}$ \\
\hline Corn & 30.94 & 32.01 & 40.61 & 8.75 & 9.92 & 23.19 & 24.21 & 20.42 & 7.27 & -9.59 & -1.23 & 14.84 \\
\hline Paddy & 31.47 & 32.54 & 41.14 & 9.28 & 10.45 & 23.72 & 24.74 & 20.95 & 7.80 & -9.06 & -0.70 & 15.37 \\
\hline Soybean & 29.24 & 30.31 & 38.91 & 7.05 & 8.22 & 21.49 & 22.51 & 18.72 & 5.57 & -11.26 & -2.93 & 13.14 \\
\hline Wheat & 16.36 & 17.43 & 26.03 & -5.83 & -4.66 & 8.61 & 9.63 & 5.84 & -7.31 & -24.17 & -15.81 & 0.26 \\
\hline Meadow & 30.27 & 31.34 & 39.94 & 8.08 & 9.25 & 22.52 & 23.54 & 19.75 & 6.60 & -10.26 & -1.90 & 14.17 \\
\hline Poplar & 16.66 & 17.73 & 26.33 & -5.53 & -4.66 & 8.91 & 9.93 & 6.14 & -7.01 & -23.87 & -15.51 & 0.56 \\
\hline Pine & 22.49 & 23.56 & 32.16 & 0.3 & 1.47 & 14.74 & 15.76 & 11.97 & -1.18 & -18.04 & -9.68 & 6.39 \\
\hline Bare land & 26.68 & 27.75 & 36.35 & 4.49 & 5.66 & 18.93 & 19.95 & 16.16 & 3.01 & -13.85 & -5.49 & 10.58 \\
\hline Urban & 32.87 & 33.94 & 42.54 & 10.68 & 11.85 & 25.12 & 26.14 & 22.35 & 9.20 & -7.66 & 0.7 & 16.77 \\
\hline Water & 43.69 & 44.76 & 53.36 & 21.50 & 22.67 & 35.94 & 36.96 & 33.17 & 20.02 & 3.66 & 11.52 & 27.59 \\
\hline Dried area & 38.15 & 39.22 & 47.82 & 15.96 & 17.13 & 30.40 & 31.42 & 27.63 & 14.48 & -2.38 & 5.98 & 22.05 \\
\hline $\begin{array}{l}\text { Deforest } \\
\text { area }\end{array}$ & 4.28 & 5.35 & 13.95 & -17.91 & -16.74 & -3.47 & -2.45 & -6.24 & -19.39 & -36.25 & -27.89 & 11.82 \\
\hline
\end{tabular}


constant group, another for increasing group, among the 11 classes, Deforest area has the middle value of 11.83 , as the thresholds should be integer value, corresponding to the scaled NDVI digital number, thus the threshold $\xi_{2}$ was decided as 11 . For the decreasing group, only one class has minus change of -5.83 , generally, all the integer value between 0 and -5 can be used as the threshold, here, we selected the middle value of -2 as the threshold $\xi_{1}$.

$\alpha$ and $\beta$ are user-specified parameters which control the degree of consistency between the temporal data, they were determined experimentally using the overall classification accuracy. Several different values of $\alpha$ and $\beta$ were tested to select the best values. The sensitivity of the Temporal Fusion Classification model with respect to the parameters $\alpha$ and $\beta$ are shown in Figure 4 ( a ) and (b). The classification performance was observed to increase as becomes larger to a certain value and to level off thereafter. The classification result was not so sensitive to the value $\alpha$ if it was large enough, but was very sensitive to parameter $\beta$. Through an inspection of these results, the optimal choice $(a=0.6$ and $\beta=0.0$ ) was made that the classification performance was best. Here, $\beta=0.0$ is interesting, but we think this is reasonable because the areas where land use change occurred are treated as independent classes, i. e., dried area and deforest area, and no land use change occurred in the other classes. In this

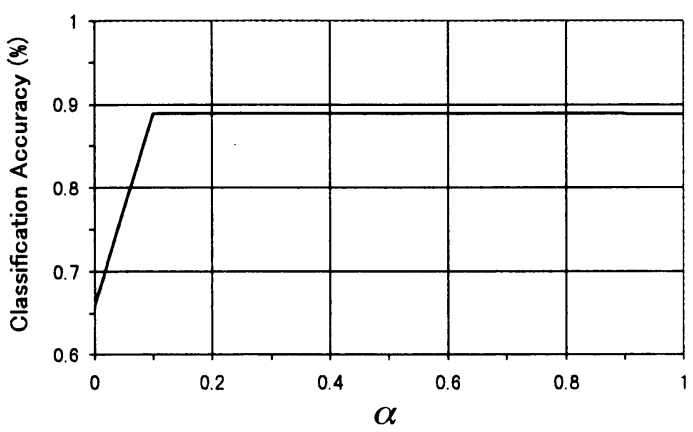

(a) research, we have not studied automatic parameter estimation of these parameters. The parameter values used were determined empirically in a limited experimental study. A small-scale sensitivity analysis with respect to these parameters indicated that a range of parameter values resulted in comparable classifier performance. However, an automatic parameter estimation method for the Temporal Fusion Classification model is desirable, but difficult to establish.

The a priori probabilities $P\left(\nu_{k}\right)$ are all approximated as being equal.

\section{RESULTS AND DISCUSSION}

The performances of the proposed Temporal Fusion Classification (TFC) technique are assessed in the following and compared with the conventional Maximum Likelihood Classification (MLC) method and the Cascade Classifier (CC) developed by Swain $^{3)}$. The Cascade Classifier also uses the transition probabilities $P\left(\nu_{k} \mid \omega_{i}\right)$, which represent the temporal dependence between images, and showed improved accuracy compared to the MLC method, but the transition probabilities used are defined empirically.

To provide a reference for comparison, the single period images are first analyzed separately, as shown in Table 2 ( $a$ ) and ( b ), the performances of the MLC method are $73.3 \%$ correct for the May

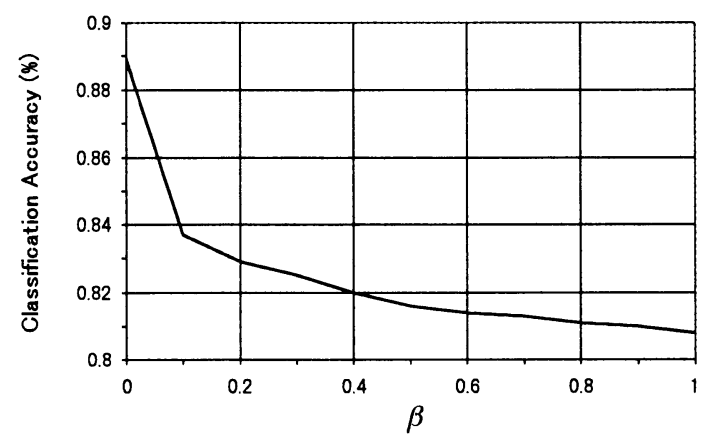

(b)

Figure 4 Sensitivity of model parameters with respect to classification accuracy. (a) Sensitivity of $\alpha$ when $\beta$ is kept constant. (b) Sensitivity of $\beta$ when $\alpha$ is kept constant. 
Table 2 Maximum likelihood classification results using single period TM data acquired in (a) May 1994 and (b) August 1994.

(a) overall accuracy $=73.3 \%$

\begin{tabular}{|c|c|c|c|c|c|c|c|c|c|c|c|c|}
\hline \multirow{2}{*}{$\begin{array}{l}\text { Classification } \\
\text { results }\end{array}$} & \multicolumn{12}{|c|}{ Ground truth classes } \\
\hline & Corn & Paddy & Bean & Wheat & Meadow & Poplar & Pine & $\begin{array}{l}\text { Bare } \\
\text { land }\end{array}$ & Urban & Water & $\begin{array}{l}\text { Dried } \\
\text { area }\end{array}$ & $\begin{array}{l}\text { Deforest } \\
\text { area }\end{array}$ \\
\hline Corn & 768 & 17 & 594 & 0 & 9 & 0 & 0 & 59 & 21 & 4 & 0 & 0 \\
\hline Paddy & 29 & 688 & 0 & 0 & 4 & 0 & 74 & 0 & 28 & 83 & 4 & 0 \\
\hline Soybean & 121 & 2 & 482 & 0 & 0 & 1 & 0 & 105 & 0 & 0 & 0 & 0 \\
\hline Wheat & 10 & 0 & 0 & 527 & 4 & 98 & 0 & 6 & 0 & 1 & 0 & 0 \\
\hline Meadow & 10 & 7 & 0 & 26 & 888 & 9 & 0 & 1 & 6 & 3 & 0 & 0 \\
\hline Poplar & 36 & 65 & 0 & 48 & 39 & 751 & 22 & 69 & 3 & 17 & 4 & 113 \\
\hline Pine & 0 & 63 & 0 & 0 & 0 & 1 & 608 & 5 & 0 & 6 & 0 & 0 \\
\hline Bare land & 20 & 39 & 5 & 41 & 3 & 114 & 150 & 326 & 0 & 25 & 0 & 2 \\
\hline Urban & 24 & 193 & 0 & 13 & 88 & 19 & 3 & 1 & 754 & 71 & 2 & 0 \\
\hline Water & 0 & 4 & 0 & 0 & 0 & 0 & 0 & 0 & 0 & 601 & 39 & 0 \\
\hline Dried area & 0 & 6 & 0 & 0 & 0 & 0 & 0 & 0 & 4 & 219 & 967 & 0 \\
\hline Deforest & 0 & 0 & 0 & 0 & 0 & 15 & 0 & 0 & 0 & 0 & 0 & 660 \\
\hline Total & 1018 & 1084 & 1081 & 655 & 1035 & 1008 & 857 & 572 & 816 & 1030 & 1016 & 775 \\
\hline $\begin{array}{c}\text { Accuracy } \\
\%\end{array}$ & 75.4 & 63.5 & 44.6 & 80.5 & 85.8 & 74.5 & 70.9 & 57.0 & 92.4 & 58.3 & 95.2 & 85.2 \\
\hline
\end{tabular}

(b) overall accuracy $=73.1 \%$

\begin{tabular}{|c|c|c|c|c|c|c|c|c|c|c|c|c|}
\hline \multirow{2}{*}{$\begin{array}{l}\text { Classification } \\
\text { results }\end{array}$} & \multicolumn{12}{|c|}{ Ground truth classes } \\
\hline & Corn & Paddy & Bean & Wheat & Meadow & Poplar & Pine & $\begin{array}{l}\text { Bare } \\
\text { land }\end{array}$ & Urban & Water & $\begin{array}{l}\text { Dried } \\
\text { area }\end{array}$ & $\begin{array}{l}\text { Deforest } \\
\text { area }\end{array}$ \\
\hline Corn & 552 & 35 & 114 & 1 & 0 & 167 & 22 & 0 & 10 & 0 & 0 & 0 \\
\hline Paddy & 0 & 986 & 1 & 0 & 0 & 5 & 17 & 0 & 7 & 0 & 0 & 0 \\
\hline Soybean & 341 & 0 & 893 & 0 & 0 & 38 & 1 & 10 & 0 & 0 & 0 & 0 \\
\hline Wheat & 0 & 0 & 0 & 561 & 481 & 23 & 0 & 0 & 6 & 0 & 0 & 0 \\
\hline Meadow & 1 & 0 & 0 & 38 & 427 & 24 & 0 & 0 & 86 & 4 & 56 & 0 \\
\hline Poplar & 65 & 4 & 47 & 1 & 33 & 568 & 187 & 115 & 0 & 0 & 0 & 81 \\
\hline Pine & 41 & 38 & 0 & 4 & 1 & 0 & 483 & 0 & 0 & 0 & 0 & 19 \\
\hline Bare land & 5 & 0 & 21 & 0 & 0 & 1 & 0 & 438 & 25 & 0 & 62 & 0 \\
\hline Urban & 12 & 21 & 5 & 47 & 89 & 158 & 16 & 9 & 675 & 105 & 76 & 0 \\
\hline Water & 0 & 0 & 0 & 0 & 1 & 0 & 0 & 0 & 6 & 921 & 0 & 0 \\
\hline Dried area & 0 & 0 & 0 & 3 & 3 & 0 & 0 & 0 & 1 & 0 & 822 & 0 \\
\hline Deforest & 1 & 0 & 0 & 0 & 0 & 24 & 131 & 0 & 0 & 0 & 0 & 675 \\
\hline Total & 1018 & 1084 & 1081 & 655 & 1035 & 1008 & 857 & 572 & 816 & 1030 & 1016 & 775 \\
\hline $\begin{array}{c}\text { Accuracy } \\
\%\end{array}$ & 54.2 & 91.0 & 82.6 & 85.6 & 41.3 & 56.3 & 56.4 & 76.6 & 82.7 & 89.4 & 80.9 & 87.1 \\
\hline
\end{tabular}

1994 data and $73.1 \%$ correct for the August 1994 data. The benefits of using multitemporal data are clearly demonstrated in Table 3 , the results of multitemporal classification are substantially better than either of single period performances. The results of the CC method are derived like this: let the transition probabilities $P\left(\nu_{k} \mid \omega_{i}\right)=1.0,0.9,0.8$, 0.7 , for $\omega_{i}=\nu_{k}$, and $P\left(\nu_{k} \mid \omega_{i}\right)=0.0,0.1,0.2,0.3$, for $\omega_{i} \neq \nu_{k}$, respectively, then perform classification using different scheme of the transition probabilities and select the best results. The best overall accuracy of the CC method is $87.3 \%$ when $P\left(\nu_{k} \mid \omega_{i}\right)=$
0.0 , for $\omega_{i} \neq \nu_{k}$ and $P\left(\nu_{k} \mid \omega_{i}\right)=1.0,0.9,0.8$, for $\omega_{i}=$ $\nu_{k}$. This is truly better than the MLC method of 85.5\% correct performance. However, the best results are demonstrated by the proposed TFC method, in which the temporal dependence of images is considered and the transition probabilities are estimated directly from the change pattern of NDVI, and show an overall accuracy of $88.9 \%$, furthermore, the computation time using the TFC method is less than half of the time used by the MLC method.

For a visual impression of the results derived by 
Table 3 Classification results using multitemporal TM data acquired in May and August 1994.

(a) Maximum likelihood method, (b ) Cascade classifier, (c) Temporal data fusion method.

(a) overall accuracy $=85.5 \%$

\begin{tabular}{|c|c|c|c|c|c|c|c|c|c|c|c|c|}
\hline \multirow{2}{*}{$\begin{array}{l}\text { Classification } \\
\text { results }\end{array}$} & \multicolumn{12}{|c|}{ Ground truth classes } \\
\hline & Corn & Paddy & Bean & Wheat & Meadow & Poplar & Pine & $\begin{array}{l}\text { Bare } \\
\text { land }\end{array}$ & Urban & Water & $\begin{array}{l}\text { Dried } \\
\text { area }\end{array}$ & $\begin{array}{l}\text { Deforest } \\
\text { area }\end{array}$ \\
\hline Corn & 869 & 37 & 237 & 0 & 0 & 0 & 0 & 6 & 0 & 1 & 0 & 0 \\
\hline Paddy & 0 & 943 & 0 & 0 & 0 & 0 & 1 & 0 & 0 & 2 & 0 & 0 \\
\hline Soybean & 121 & 0 & 833 & 0 & 0 & 0 & 0 & 25 & 0 & 0 & 0 & 1 \\
\hline Wheat & 0 & 0 & 0 & 552 & 7 & 28 & 0 & 0 & 0 & 0 & 0 & 1 \\
\hline Meadow & 0 & 0 & 0 & 48 & 955 & 0 & 0 & 0 & 3 & 8 & 0 & 0 \\
\hline Poplar & 19 & 1 & 9 & 1 & 2 & 867 & 93 & 92 & 0 & 2 & 0 & 95 \\
\hline Pine & 0 & 2 & 0 & 0 & 0 & 2 & 648 & 0 & 0 & 0 & 0 & 0 \\
\hline Bare land & 0 & 0 & 2 & 0 & 0 & 1 & 0 & 447 & 1 & 0 & 0 & 0 \\
\hline Urban & 9 & 1 & 0 & 54 & 71 & 102 & 115 & 2 & 811 & 122 & 150 & 0 \\
\hline Water & 0 & 0 & 0 & 0 & 0 & 0 & 0 & 0 & 0 & 895 & 1 & 0 \\
\hline Dried area & 0 & 0 & 0 & 0 & 0 & 0 & 0 & 0 & 1 & 0 & 865 & 0 \\
\hline Deforest & 0 & 0 & 0 & 0 & 0 & 8 & 0 & 0 & 0 & 0 & 0 & 678 \\
\hline Total & 1018 & 1084 & 1081 & 655 & 1035 & 1008 & 857 & 572 & 816 & 1030 & 1016 & 775 \\
\hline $\begin{array}{c}\text { Accuracy } \\
\%\end{array}$ & 85.4 & 87.0 & 77.1 & 84.3 & 92.3 & 86.0 & 75.6 & 78.1 & 99.4 & 86.9 & 85.1 & 87.5 \\
\hline
\end{tabular}

(b) overall accuracy $=87.3 \%$

\begin{tabular}{|c|c|c|c|c|c|c|c|c|c|c|c|c|}
\hline \multirow{2}{*}{$\begin{array}{l}\text { Classification } \\
\text { results }\end{array}$} & \multicolumn{12}{|c|}{ Ground truth classes } \\
\hline & Corn & Paddy & Bean & Wheat & Meadow & Poplar & Pine & $\begin{array}{l}\text { Bare } \\
\text { land }\end{array}$ & Urban & Water & $\begin{array}{l}\text { Dried } \\
\text { area }\end{array}$ & $\begin{array}{l}\text { Deforest } \\
\text { area }\end{array}$ \\
\hline Corn & 820 & 3 & 209 & 0 & 0 & 0 & 0 & 5 & 0 & 0 & 0 & 0 \\
\hline Paddy & 1 & 936 & 0 & 0 & 0 & 0 & 0 & 0 & 0 & 4 & 0 & 0 \\
\hline Soybean & 140 & 0 & 851 & 0 & 0 & 0 & 0 & 24 & 0 & 0 & 0 & 0 \\
\hline Wheat & 0 & 0 & 0 & 605 & 16 & 17 & 0 & 0 & 0 & 0 & 0 & 0 \\
\hline Meadow & 0 & 0 & 0 & 22 & 949 & 1 & 0 & 0 & 9 & 6 & 0 & 0 \\
\hline Poplar & 50 & 47 & 5 & 8 & 15 & 952 & 128 & 97 & 0 & 2 & 0 & 78 \\
\hline Pine & 0 & 11 & 0 & 0 & 0 & 1 & 683 & 0 & 0 & 0 & 0 & 0 \\
\hline Bare land & 4 & 0 & 16 & 0 & 0 & 3 & 0 & 446 & 3 & 0 & 0 & 1 \\
\hline Urban & 3 & 87 & 0 & 20 & 55 & 32 & 45 & 0 & 803 & 121 & 101 & 0 \\
\hline Water & 0 & 0 & 0 & 0 & 0 & 0 & 0 & 0 & 0 & 897 & 1 & 0 \\
\hline Dried area & 0 & 0 & 0 & 0 & 0 & 0 & 0 & 0 & 1 & 0 & 914 & 0 \\
\hline Deforest & 0 & 0 & 0 & 0 & 0 & 2 & 1 & 0 & 0 & 0 & 0 & 696 \\
\hline Total & 1018 & 1084 & 1081 & 655 & 1035 & 1008 & 857 & 572 & 816 & 1030 & 1016 & 775 \\
\hline $\begin{array}{c}\text { Accuracy } \\
\%\end{array}$ & 80.6 & 86.3 & 78.7 & 92.4 & 91.7 & 94.4 & 79.7 & 78.0 & 98.4 & 87.1 & 90.0 & 89.8 \\
\hline
\end{tabular}

(c) overall accuracy $=88.9 \%$

\begin{tabular}{|c|c|c|c|c|c|c|c|c|c|c|c|c|}
\hline \multirow{2}{*}{$\begin{array}{l}\text { Classification } \\
\text { results }\end{array}$} & \multicolumn{12}{|c|}{ Ground truth classes } \\
\hline & Corn & Paddy & Bean & Wheat & Meadow & Poplar & Pine & $\begin{array}{l}\text { Bare } \\
\text { land }\end{array}$ & Urban & Water & $\begin{array}{l}\text { Dried } \\
\text { area }\end{array}$ & $\begin{array}{l}\text { Deforest } \\
\text { area }\end{array}$ \\
\hline Corn & 854 & 22 & 210 & 0 & 0 & 0 & 0 & 5 & 0 & 2 & 0 & 0 \\
\hline Paddy & 2 & 1006 & 0 & 0 & 0 & 0 & 0 & 0 & 1 & 4 & 0 & 0 \\
\hline Soybean & 147 & 0 & 851 & 0 & 0 & 1 & 1 & 26 & 0 & 0 & 0 & 0 \\
\hline Wheat & 0 & 0 & 0 & 593 & 6 & 16 & 0 & 0 & 0 & 0 & 0 & 0 \\
\hline Meadow & 0 & 0 & 0 & 30 & 959 & 1 & 0 & 0 & 9 & 6 & 0 & 0 \\
\hline Poplar & 10 & 16 & 3 & 4 & 15 & 946 & 97 & 59 & 0 & 2 & 0 & 89 \\
\hline Pine & 0 & 13 & 0 & 0 & 0 & 1 & 745 & 0 & 0 & 0 & 0 & 0 \\
\hline Bare land & 4 & 0 & 17 & 0 & 0 & 8 & 8 & 482 & 1 & 0 & 0 & 0 \\
\hline Urban & 1 & 27 & 0 & 28 & 55 & 33 & 6 & 0 & 804 & 119 & 101 & 0 \\
\hline Water & 0 & 0 & 0 & 0 & 0 & 0 & 0 & 0 & 0 & 897 & 1 & 0 \\
\hline Dried area & 0 & 0 & 0 & 0 & 0 & 0 & 0 & 0 & 1 & 0 & 914 & 0 \\
\hline Deforest & 0 & 0 & 0 & 0 & 0 & 2 & 0 & 0 & 0 & 0 & 0 & 686 \\
\hline Total & 1018 & 1084 & 1081 & 655 & 1035 & 1008 & 857 & 572 & 816 & 1030 & 1016 & 775 \\
\hline $\begin{array}{c}\text { Accuracy } \\
\% \\
\end{array}$ & 83.9 & 92.8 & 78.7 & 90.5 & 92.7 & 93.8 & 86.9 & 84.3 & 98.5 & 87.1 & 90.0 & 88.5 \\
\hline
\end{tabular}




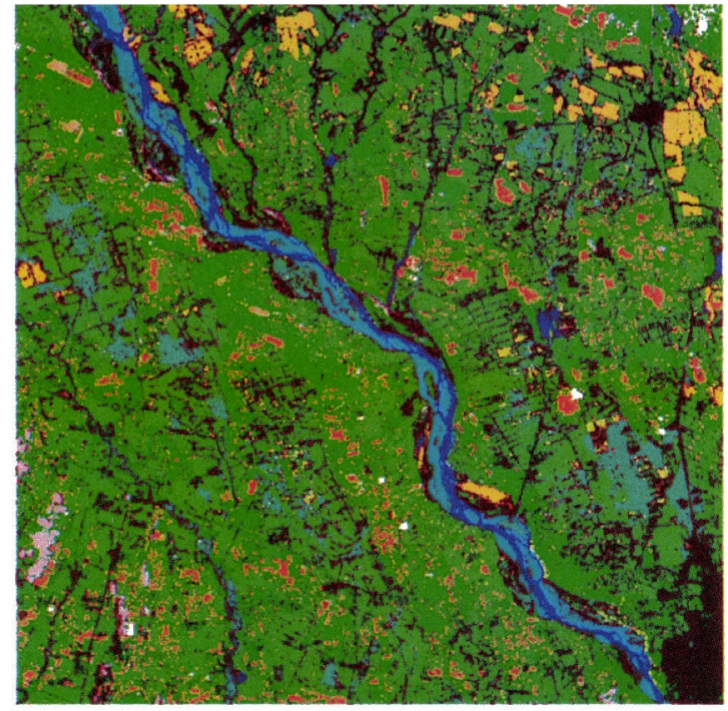

(a)

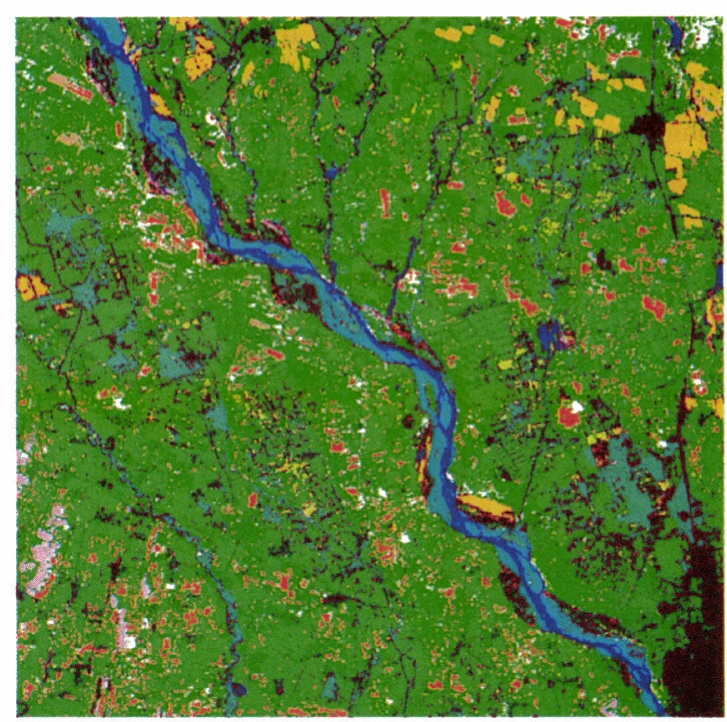

(b)

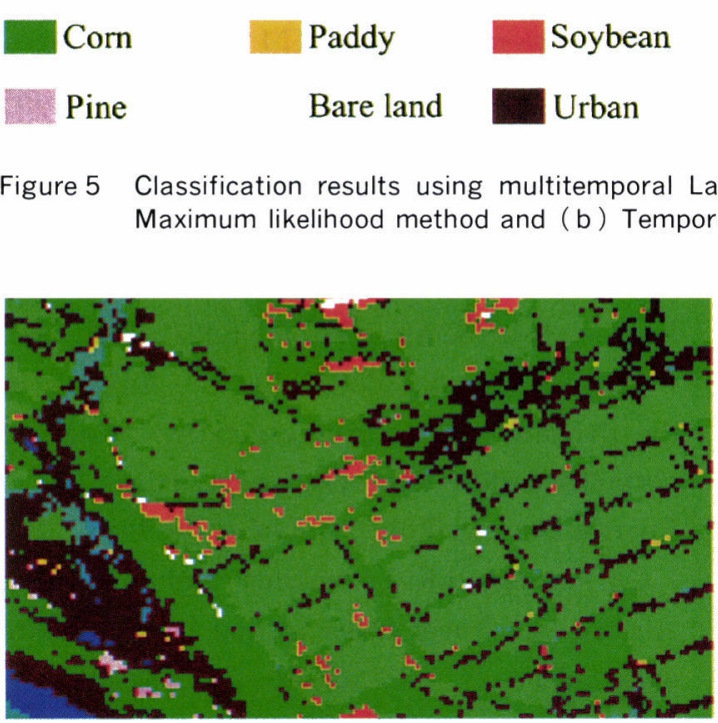

( a )
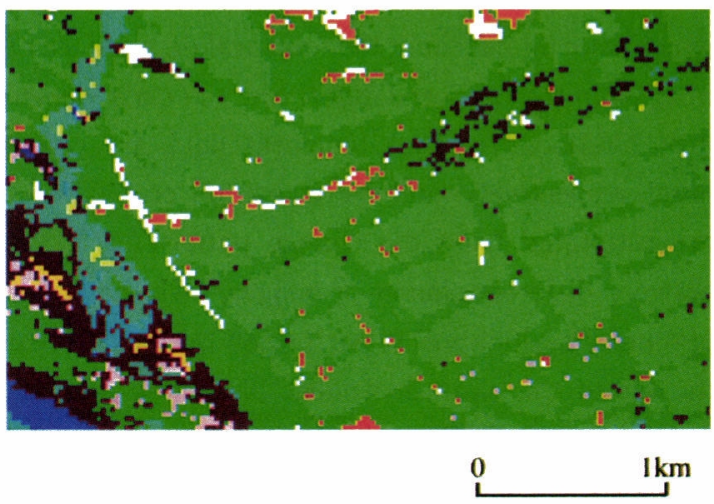

( b )

Figure 6 Subscene of the classification results using multitemporal Landsat TM data. (a) Maximum likelihood method and ( b ) Temporal data fusion method.

the proposed TFC method, as shown in Figure 5 (b), almost all classes are well classified, especially paddy, wheat, meadow, poplar and urban, which arrive an accuracy of more than $90 \%$, The areas, like dried area and deforest area, where land use change occurred, are also well detected. The vegetation and non-vegetation areas and the differ- ent crops and forests are clearly distinguished. The misclassified pixels mainly exist in the classes between corn and soybean, poplar and pine, urban and water, urban and dried area, also poplar and deforest area. Compared to the results of the MLC method shown in Figure 5(a), although the classification accuracy of corn is a little lower than that of 
the MLC method, the results of other classes are much more better. We can see more clearly and minutely in Figure 6, it shows the subscene of the classification results using the MLC method and the TFC method, respectively. There are so many misclassified pixels between corn and soybean, meadow and urban, especially urban and sparse poplar in Figure 6(a), but they are clearly and correctly classified in Figure 6(b). These prove that the proposed TFC method is very sensitive and indeed can solve the problem of agricultural area and non-agricultural area discrimination and crop identification.

\section{CONCLUSION}

We proposed a new method based on the Bayesian formulation and try to solve the problem of how to discriminate agricultural area and non -agricultural area and different crops using multitemporal Landsat TM data. This is a statistical method based on multitemporal data fusion, which take into account the temporal dependence of images. In the proposed algorithm, the class-dependent likelihood of multitemporal data are calculated, respectively, and the transition probabilities are estimated from the change pattern of NDVI between different classes of images, then the Bayes optimal classification is performed by maximizing the set of the class-dependent likelihood and the transition probabilities. This method can also be used as an alternative method for change detection of land cover and land use.

The temporal fusion model that we presented is thought to successfully incorporate the temporal dependence in the classification process and reasonably allow the transition probabilities to be estimated directly from the change pattern of NDVI, resulting in improved classification accuracy, moreover, reduce the dimensionality of the probability functions used and facilitate the computation over time.

\section{REFERENCES}

1) J.R. Schriever and R. Congalton: Evaluatingseasonal variability as an aid to cover-type mapping from Landsat Thematic Mapper data in the northeast, Photogrammetric Engineering \& Remote Sensing, 61, 321-327, 1995.

2 ) H. Middelkoop and L.L.F. Janssen: Implementation of Temporal Relationships in Knowledge Based Classification of Satellite Images, Photogrammetric Engineering \& Remote Sensing, Vol. 57, pp.937-945, 1991.

3 ) P.H. Swain: Bayesian classification in a time -varying environment, IEEE Trans. Syst., Man, Cybern, Vol. SMC-8, pp.879-883, 1978.

4 ) A.H. Schistad Solberg, A.K. Jain and T. Taxt: MultiSource classification of Remotely Sensed Data: Fusion of Landsat TM and SAR Images, IEEE Trans. Geosci. Remote sensing, Vol. 32, pp. 768-777, 1994.

5 ) C.O. Justice, J.R. Townshend, B.N. Holben and C.J. Tucker: Analysis of the phenology of global vegetation using meteorological satellite data, Int. J. Remote Sensing, Vol. 6, pp.1271-1318, 1985.

6 ) J.R. Townshend and C.O. Justice: Analysis of the dynamics of African vegetation using the normalized difference vegetation index, Int. J. Remote Sensing, Vol. 7, pp.1435-1446, 1986.

7 ) C.J. Tucker, J.R. Townshend and T.E. Goff : African land-cover classification using satellite data, Science, Vol. 227, pp.369-375, 1985.

8 ) L. Bruzzone and S.B. Serpico: An Iterative Technique for the Detection of Land-Cover Transitions in Multitemperal Remote-Sensing Images, IEEE Trans. Geosci. Remote sensing, Vol. 35, pp. 858-867, 1997.

9 ) J.Piper: Variability and bias in experimentally measured classifier error rates, Pattern Recognition Letters, Vol. 13, pp.685-692, 1992.

10) H. Oguma and Y. Yamagata : Study on Effective Observing Season Selection to Produce the Wetland Vegetation Map, Journal of the Japan Society of Photogrammetry and Remote Sensing, Vol. 36, No. 4, pp.5-16, 1997. 